\title{
Fabrication of ZnO Nanowire Device Using Top-Down Approach
}

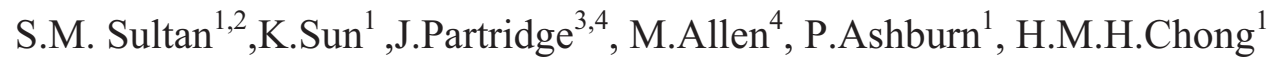 \\ ${ }^{1}$ Nano Research Group, School of Electronics and Computer Science, University of Southampton, Highfield, SO17 1BJ, \\ UK Tel: ++44(0)23 8059 3777, Fax: +44(0)23 8059 3029, email: sms08r@ecs.soton.ac.uk \\ ${ }^{2}$ Faculty of Electrical Engineering, Universiti Teknologi Malaysia (UTM), Skudai Campus, 81310 Johor, Malaysia \\ ${ }^{3}$ University of Canterbury, New Zealand \\ ${ }^{4}$ The McDiarmid Institute for Advanced Materials and Nanotechnology, New Zealand
}

\begin{abstract}
1. Abstract
$\mathrm{ZnO}$ nanowire devices were fabricated from top-down using optical lithography. The nanowires are formed from anisotropic etch of $100 \mathrm{~nm}$ Filtered Cathodic Vacuum Arc (FCVA) deposited $\mathrm{ZnO}$ thin film. The nanowires are characterized using SEM and Raman spectroscopy via image mapping. The current-voltage characteristics showed a typical ohmic behaviour after contact annealing, reflecting the influence of the lowering of contact barriers between the $\mathrm{ZnO}$ nanowire device and the $\mathrm{Al}$ metal electrode.
\end{abstract}

\section{Introduction}

$\mathrm{ZnO}$ nanowires are considered to be one of the most important semiconductor nanomaterials with applications such as optoelectronics, electronics and sensors due to their wide and direct bandgap energy (3.37 eV), large exciton binding energy (60 meV) and high thermal stability[1-3]. To date, a lot of research is done to produce high quality nanowires from bottom-up approach [4]. Top-down method using electron-beam and focused-ion-beam lithography [5-6] have also made great impact to investigate the basic properties of nanowire devices but their use on a large scale is a challenge due to high cost.

Recently, polycrystalline silicon nanowires are patterned using top-down optical lithography which was used in biosensor applications [7]. In this work, we have demonstrated a top-down silicon compatible process to create $\mathrm{ZnO}$ nanowire devices and experimentally verified its Ohmic conductivity.

\section{Experiment}

Figure 1 shows the process steps of the $\mathrm{ZnO}$ nanowire fabrication process. The process starts with an n-type $\mathrm{Si}$ sample and a layer of $400 \mathrm{~nm} \mathrm{SiO}_{2}$ is thermally grown on the substrate. The $\mathrm{SiO}_{2}$ trench is formed by photolithography pattern transfer and reactive ion etching (RIE) based on $\mathrm{CHF}_{3}-\mathrm{Ar}$ gas mixture. The etched depth of the $\mathrm{SiO}_{2}$ trench is $100 \mathrm{~nm}$. A layer of $100 \mathrm{~nm}$ thick $\mathrm{ZnO}$ is deposited on top of the trench structure using Filtered Cathodic Vacuum Arc (FCVA) method, as shown in the SEM of Figure 2(a). The $\mathrm{ZnO}$

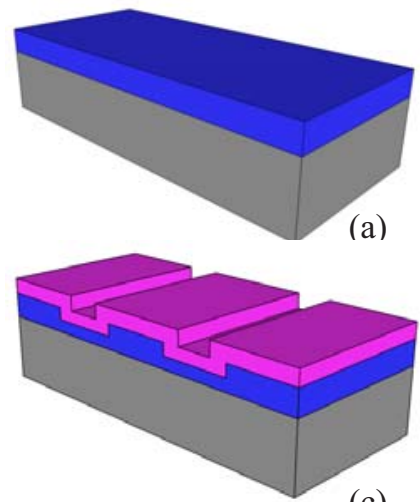

(c) n-Si substrate

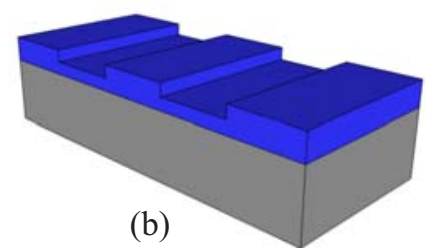

(b)

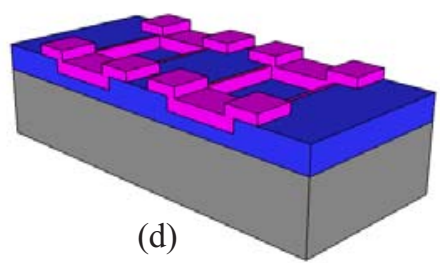

(d)

$\mathrm{SiO}_{2}$

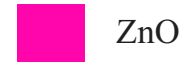

Fig.1: Diagram illustrating the fabrication process of the $\mathrm{ZnO}$ nanowire (a) thermal $\mathrm{SiO}_{2}$ deposition, (b) $\mathrm{SiO}_{2}$ patterned and etched using RIE (c) ZnO FCVA (d) ZnO nanowire formed at the spacer after RIE etch

film is then etched anisotropically using RIE to form the nanowire structure as shown in Figure 2(b). The etch gas used was $\mathrm{CHF}_{3}$ and the RF power is varied from $100 \mathrm{~W}$ to $200 \mathrm{~W}$ to determine the best selectivity between $\mathrm{ZnO}$ and $\mathrm{SiO}_{2}$. The etch pressure was 20 mTorr and the gas flow rate was set at $25 \mathrm{sccm}$. The etch rate results are shown in Figure 3.

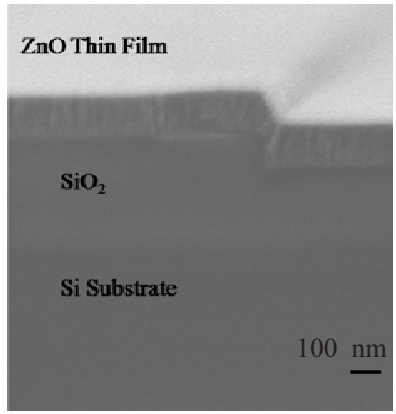

(a)

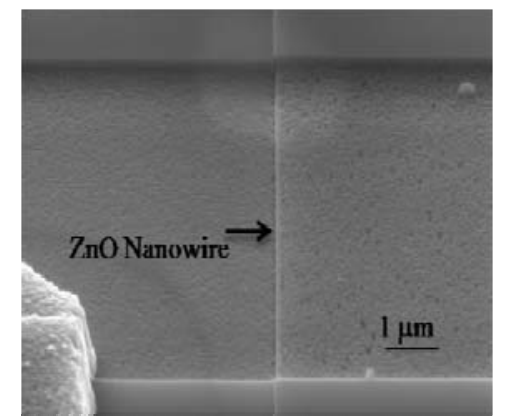

(b)
Fig.2: SEM images of (a) $\mathrm{ZnO}$ thin film on $\mathrm{SiO}_{2}$ trench. (b) $\mathrm{ZnO}$ nanowire formed at the $\mathrm{SiO}_{2}$ spacer 
The etch rate results demonstrating highest etch rate of $1.64 \mathrm{~nm} / \mathrm{min}$ for RF power of $200 \mathrm{~W}$, followed by 0.72 $\mathrm{nm} / \mathrm{min}$ and $0.3 \mathrm{~nm} / \mathrm{min}$ for RF power of $150 \mathrm{~W}$ and $100 \mathrm{~W}$, respectively.

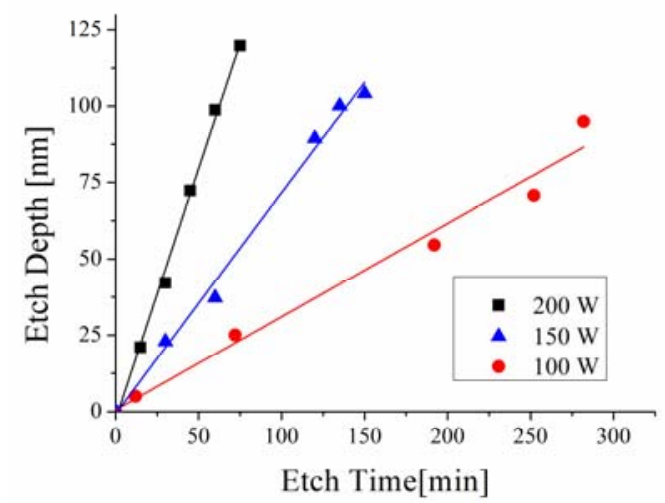

Fig.3: The etch rate of $\mathrm{ZnO}$ film with pressure $=20 \mathrm{mTorr}$ and $\mathrm{CHF}_{3}=25 \mathrm{sccm}$

We have selected RIE power of 200W not only due to its highest etch rate but at this power, highest selectivity was achieved compared to the $\mathrm{SiO}_{2}$ layer beneath the $\mathrm{ZnO}$ film. Finally, Al contact pad was e-beam evaporated on top of the nanowire structure and annealed in Rapid Thermal Annealing (RTA) process at $350^{\circ} \mathrm{C}$ for 12 mins. The nanowire device structure with Al pad is shown in the optical microscopy image in Figure 4(a). The nanowires fabricated have length range from $2 \mu \mathrm{m}$ to $20 \mu \mathrm{m}$. The width and height of the $\mathrm{ZnO}$ nanowires are around $100 \mathrm{~nm}$. These dimensions can be controlled by adjusting the thickness of the $\mathrm{ZnO}$ layer and the height of the $\mathrm{SiO}_{2}$ trench. Figure 4(b) shows 16 identical wires across the two $\mathrm{Al}$ electrodes demonstrating $\mathrm{ZnO}$ nanowire arrays were successfully formed at the side of the oxide spacers.

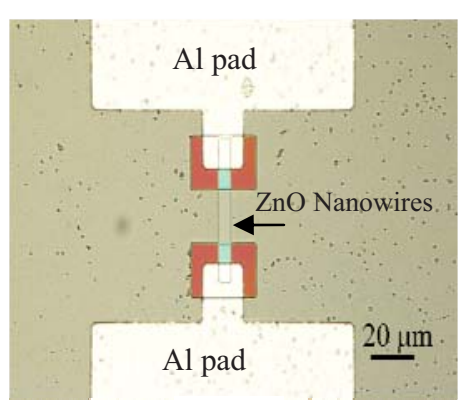

(a)

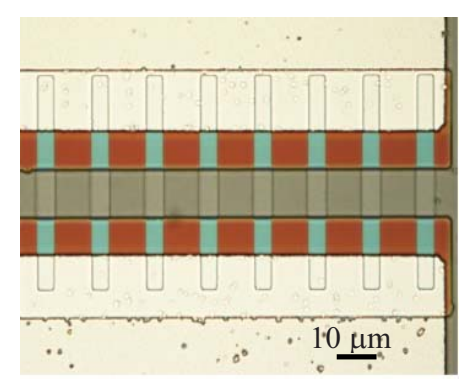

(b)
Fig.4 Optical images of (a) $\mathrm{ZnO}$ nanowires formed at the $\mathrm{SiO}_{2}$ spacer (b) Array of $\mathrm{ZnO}$ nanowires

\section{Characterization}

In this section, we characterize the $\mathrm{ZnO}$ nanowire by using Raman spectroscopy and its Ohmic characteristics. The Raman spectroscopy is done by mapping the $\mathrm{ZnO}$ nanowire at the side of the $\mathrm{SiO}_{2}$ trench as shown in Figure 5. Figure 5 (a) shows bright yellow region, indicating the presence of $\mathrm{ZnO}$ and this is verified by the Raman spectrum shown in Figure 5(d). The laser source used for the Raman spectroscopy map was $532 \mathrm{~nm}$. If the incident light was exactly normal to the surface, only the $E_{2}$ phonon modes and the $A_{1}(L O)$ phonon mode can be observed in $\mathrm{ZnO}$ [8] The peaks at $437 \mathrm{~cm}^{-1}$ should be assigned to the vibration modes of $E_{2}$. The $E_{2}$ mode was related to band characteristics of the wurtzite phase, and it can be shifted due to residual stress in the nanowire. Figure 5(a) of Sample 1 and Figure 5(b) of Sample 2 show high intensity (yellow) at the side of the oxide trench, which indicate the existence of $\mathrm{ZnO}$ nanowires. Meanwhile Figure 5(c) of Sample 3 does not show peaks at $E_{2}$ mode near the oxide trench which suggests the $\mathrm{ZnO}$ film has been overetched.
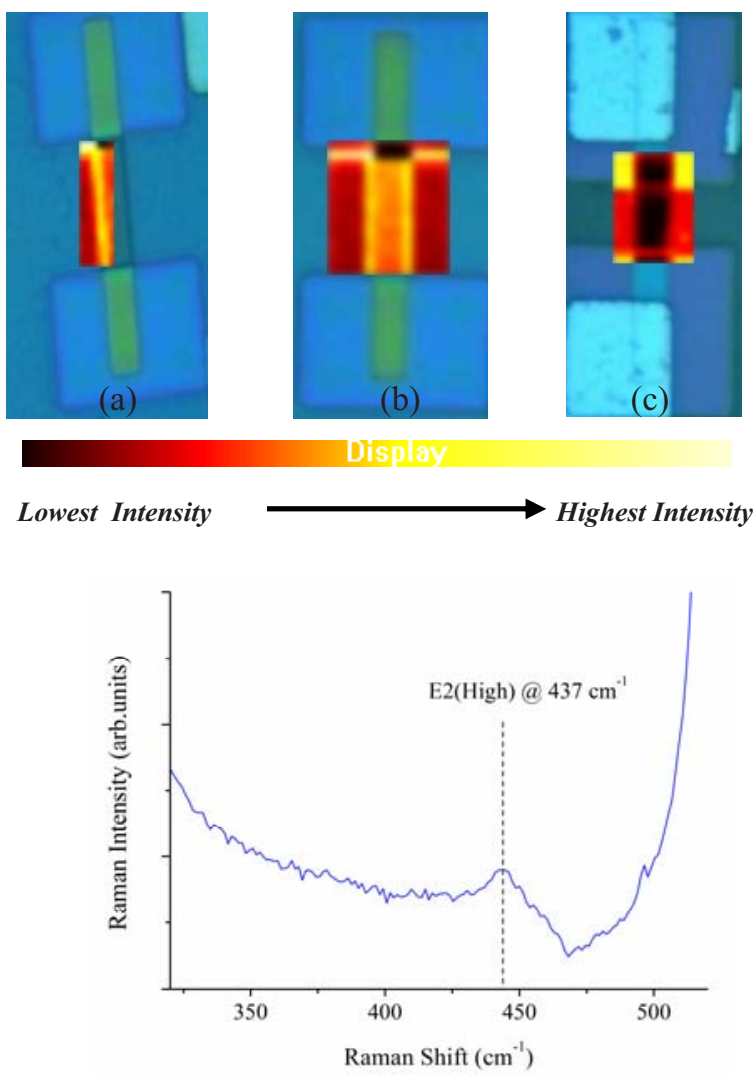

(d)

Fig.5: Raman image mapping at $E_{2}$ phonon mode (a) Sample 1 (b) Sample 2 (c) Sample 3(d) Raman spectra obtained from one of the mapped point along $\mathrm{ZnO}$ nanowire device 
The electrical characterization is done using a semiconductor parameter analyzer HP4155. Figure 6 shows the I-V characteristics of the $\mathrm{ZnO}$ nanowire device measured before and after contact annealing in RTA. The current-voltage characteristics were measured in room temperature. The nanowires measured were $10 \mu \mathrm{m}$ long. The voltage is biased from $-1 \mathrm{~V}$ to $1 \mathrm{~V}$. Before annealing, the $\mathrm{ZnO}$ nanowire device show asymmetrical behaviour with máximum current of $1 \times 10^{-8} \mathrm{~A}$ at $1 \mathrm{~V}$. This result indicates the existence of surface barriers between the $\mathrm{ZnO}$ nanowire device and the Al metal electrode. The black curve shows the same nanowire device after contact annealing with RTA in vacuum. The curve shows a distinctive characteristics of Ohmic behaviour from the symmetric I-V result. Contact annealing also improves the current of the $\mathrm{ZnO}$ nanowire device by three-fold in magnitude with máximum current achieved at $1 \mathrm{~V}$ is $2 \times 10^{-5} \mathrm{~A}$. This result using $\mathrm{Al}$ electrode is comparable to results produced using Ti/Au metal [2][9]. This is due to the dissociation of the $\mathrm{ZnO}$ at the surface región and strong reaction between $\mathrm{Al}$ and $\mathrm{O}$ in the $\mathrm{ZnO}$ layer with the annealing process. As a result, the n-type barrier heights is being lowered. [10]

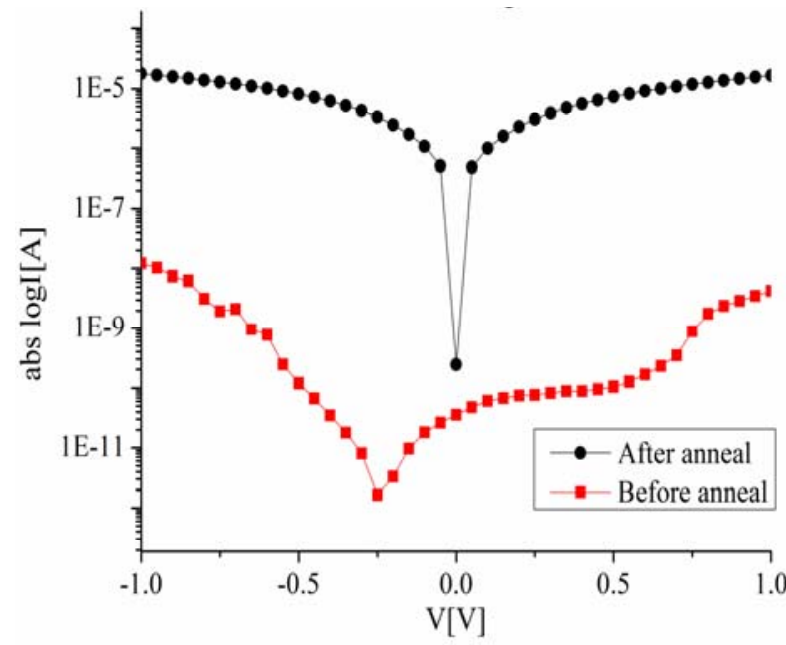

Fig.5: The I-V characteristics of Al-ZnO Nanowire Before and After Contact Anneal

\section{Conclusions}

$\mathrm{ZnO}$ nanowire structures were fabricated using topdown approach and characterized using Raman spectroscopy and its Ohmic behavior is studied. This fabrication produces large scale ordered nanowire devices and its process is compatible with Silicon CMOS process flow. We demonstrated that the dimensions and positions of the nanowires can be controlled. The fabricated $\mathrm{ZnO}$ nanowire device shows high intensity Raman peaks along the $\mathrm{SiO}_{2}$ spacer which is a good indication of the existence of $\mathrm{ZnO}$ material. The Ohmic characteristic after the RTA annealing improves with current enhanced by three fold order in magnitude. Thus, we have successfully demonstrated that this technique is a very promising method and can be directly extended to the fabrication of nanowire fieldeffect transistor.

\section{References}

[1] Y.W.Heo, D.P.Norton, L.C.Tien, Y.Kwon, B.S.Kang, F.Ren, S.J.Pearton and J.R.LaRoche, " $\mathrm{ZnO}$ nanowire growth and devices," Materials Science and Engineering R, Volume 47, 1, 2004.

[2] J.H.He, and C.H.Ho, "The study of electrical characteristics of heterojunction based on $\mathrm{ZnO}$ nanowires using ultrahigh-vacuum conducting atomic force microscopy," Applied Physics Letters, 91, 233105, 2007.

[3] P.C.Chang, Z.Fan, C.J.Chien, D.Stichtenoth, C.Ronning, and J.G.Lu, "High Performance $\mathrm{ZnO}$ nanowire Field Effect Transistors," Applied Physics Letters, 89, 133113, 2006.

[4] G.Yu, and C.M.Lieber, "Assembly and integration of semiconductor nanowires for functional nanosystems," Pure Applied Chemistry, 82, 2295-2314, 2010.

[5] W.Lu, J.Xiang, B.P.Timko, Y.Wu, and C.M.Lieber, "Onedimensional hole gas in germanium/silicon nanowire heterostructures," Proc.Natl.Acad.Sci.USA, 102, 10046$10051,2005$.

[6] C.Y.Nam, J.Y.Kim, and J.E.Fischer, "Focused-ion-beam Platinum nanopatterning for $\mathrm{GaN}$ nanowires: Ohmic contacts and patterned growth,” Applied Physics Letters, 86, 193112, 2005.

[7] S.Kai, M. M. A .Hakim, J. Kong, M. R. R. d.Planque, H.Morgan, P.L.Roach,D.E.Davis,P. Howarth, and P.Ashburn, "Polycrystalline Silicon Nanowires Patterned by Top-Down Lithography for Biosensor Applications," In: The 36th International Conference on Micro \& Nano Engineering, September 19-22, Genoa, Italy,2010.

[8] T.C.Damen, S.P.S.Porto, and B.Tell, "Raman Effect in Zinc Oxide," Physical Review, 142,570, 1966.

[9] Z.-M.Liao, K.-J.Liu, J.-M.Zhang, J.Xu, D.-P.Yu, “Effect of surface states on electron transport in individual $\mathrm{ZnO}$ nanowires," Physics Letters A, 367, 2007.

[10] H.-K.Kim, K.-K.Kim, S.-J.Park, T.-Y.Seong, I.Adesida, "Formation of low resistance nanalloyed $\mathrm{Al} / \mathrm{Pt}$ ohmic contacts on n-type $\mathrm{ZnO}$ epitaxial layer" Journal of Applied Physics, Vol.94, 6, 2003 